Article

\title{
Analysis of Factors Causing Delays in the Diesel Engine Remanufacturing Process at an Indonesian Company
}

\author{
Erwin Soeseno and Ratih Dyah Kusumastuti \\ Department of Management, Faculty of Economics and Business, Universitas Indonesia, \\ UI Campus Depok 16424, Indonesia; erwinsoeseno@gmail.com \\ * Correspondence: ratih.dyah@ui.ac.id
}

Received: 13 November 2018; Accepted: 13 December 2018; Published: 20 December 2018

check for updates

\begin{abstract}
HeavyEq is an Indonesian company that remanufactures diesel engines for the mining industry. The company experiences delays in the remanufacturing process that lead to a sales backlog. The main purpose of this paper is to identify the root cause of, and propose a solution to, the problem. A fishbone diagram is developed to identify the root cause, and the results show that delays in the remanufacturing process are mainly caused by uncertainty over cores (used engines) in terms of their arrival time, quantity, and quality. Based on a literature review and interviews with experts, an improvement in core acquisition activity, separating job orders for disassembly and recovery, and reassembly processes is proposed to reduce delays in the remanufacturing process.
\end{abstract}

Keywords: remanufacturing delay; diesel engine; root cause analysis; Indonesia

\section{Introduction}

Nowadays, issues on environmental protection and the prevention of pollution are attracting more attention in almost every country. Some of the triggers are the scarcity of natural resources, a limited landfill area, an inadequate incinerator capacity, and an increase in environmental pollution. These factors have prompted the government in certain countries to issue regulations that force the industry to be more responsible for the final disposal of its industrial waste as well as reducing its waste [1].

One way to reduce industrial waste is by conducting product recovery. According to Thierry et al. [1], product recovery management covers the management of all used and disposed goods (materials, components, and final products) that fall under the responsibility of the company for the purpose of recovering as much economic (and ecological) value as reasonably possible. One option for product recovery is remanufacturing.

Remanufacturing is value recovery from used products by reusing the durable parts for the manufacturing of a product with an original functionality [2]. Some products that it is possible to remanufacture, for instance, are disposable cameras, toner cartridges, photocopiers, and automotive parts [3]. According to Cummins Inc. [4], in practice, the remanufacturing process requires $85 \%$ less energy compared to the manufacturing of new products.

Referring to 14th edition of the APICS dictionary [5], remanufacturing is defined as an industrial process in which a worn-out product is reconditioned into its new condition. Stahel [6] states that the remanufacturing industry is considered to be economically and ecologically friendly, as it extends a product's life by reusing its parts. In the remanufacturing process, new parts are needed as the recovery rate of disassembled parts can never achieve 100\% [7]. Stahel [6] says that, on average, only about $40 \%$ of the total number of components of a remanufactured product are new components, 
and the percentage of new components may be reduced to $25 \%$, as there will be better quality parts, an improvement in quality control, and advancement in remanufacturing technology. According to the terminology of diesel engine remanufacturing, a core is a worn-out engine that shows such low performance that it needs a total repair. In heavy diesel engine remanufacturing (and other remanufacturing processes), cores are used as the main raw material [8].

In practice, it is difficult to ensure that cores (as raw material) will be collected on time according to a production schedule, because this is related to shipping a core from its location to the factory, and mainly depends on a geographic factor [8]. The late arrival of cores will affect the entire process, from the process of disassembly to the process of reassembly, as the cores will be used as raw material. Thus, the availability of cores, in terms of numbers and models/types, at the right time becomes very important [7]. Furthermore, the disassembly and salvaging/machining processes have a high level of uncertainty due to the core's condition (whether all or some of its parts need to be replaced or are still reusable [9]). The situation may cause delays in the remanufacturing process that lead to a low customer service level.

HeavyEq is an Indonesian company that remanufactures diesel engines, other components, and subcomponents, and markets its products in overseas countries. The name of the company is not revealed for confidentiality reason. The company experiences a problem in its operations that causes production delays. Thus, the objectives of this paper are to identify the root cause of the company's operations problem, and propose solutions to the problem. This paper contributes to providing insights on the operations problem that a remanufacturing company experiences, as well as providing solutions to the problem. The remainder of the paper is organized as follows. A review of the relevant literature is given in Section 2, followed by explanations of the methodology in Section 3, findings and discussion in Section 4, and conclusions and recommendations in Section 5.

\section{Literature Review}

\subsection{Remanufacturing}

The remanufacturing process is actually a type of product recovery; the other four types are repair, refurbishment, cannibalization, and recycling [1]. Repair has the objective of restoring the function of the returned product. In refurbishment, the quality of the returned product will be restored to a certain level, which is typically lower than that of new products. The goal of cannibalization is to replace broken spare parts with ones in good condition. Recycling aims to reuse the materials from the returned products. From a quality perspective, a recycled product is classified based on the location of its future positioning. Krikke [10] further divides recycling into three classes: (1) high-quality recycling material (used for original quality), (2) low-quality recycling material (used for a lower class than the original one), and (3) alternative recycling material (commonly applied to new material).

Product recovery causes the reverse flow of used and discarded products, and a closed-loop supply chain is formed when the goods flow back to their original manufacturers. A closed-loop supply chain is conventionally seen as a combination of forward material flows and reverse material flows. Closed-loop supply chain management is the design, control, and operation of a system to maximize value creation over the entire life-cycle of a product, with the dynamic recovery of value from different types and volumes of returns over time [11].

Concerning remanufacturing, in general, a remanufacturing process comprises three subprocesses, namely collection, remanufacturing, and redistribution [12]. Collection is defined as the process of collecting cores from end-users [12]. The return of these cores is important as the cores are going to be used as raw materials in remanufacturing. Having the cores available in the appropriate quantity and model/type at the right time becomes a very critical point [7]. The remanufacturing subprocess is the essence of the remanufacturing process. According to Steinhilper [13], the remanufacturing subprocess consists of disassembly (i.e., each core is disassembled to its smallest parts, then each of the parts is identified), cleaning (not only a washing process, but also removing paint, oil/lubricant, grease, 
and corrosion residue from the parts), and inspection (whose objectives are to determine condition of the parts and to decide the suitable reconditioning method for the parts' conditions). Reconditioning is the process of restoring the parts to their new condition (this covers not only geometric recovery, but also the material features, such as hardening). Reassembly is the assembly of all the reused and new parts, and testing is ensuring that the parts' quality meets the quality standard of the new parts. In the redistribution subprocess, the remanufactured products are shipped to customers, the potential market, or a warehouse. This subprocess includes transportation and storage activities [14].

Remanufacturing may continue to grow due to an increase in the regulatory pressures felt by manufacturers to produce goods in an environmentally friendly manner, and due to the recognized economic benefit [15].

\subsection{The Remanufacturing Industry}

According to Steinhilper et al. [16], the strongest tradition of remanufacturing exists in the automotive industry. They further state that about two-thirds of all remanufacturing occurs in the automotive industry. According to data from the U.S. Department of Commerce [17], the total value of remanufactured automotive parts in the U.S. was about USD 40 billion in 2010, and the total value of the global remanufactured automotive parts industry is estimated to be the range of USD 85-100 billion.

According to Tian et al. [18], remanufacturing production companies can be classified into original equipment manufacturer (OEM) remanufacturing companies (a form of extended producer responsibility, in which the company is directly engaged in component remanufacturing activity), independent remanufacturing companies (companies that remanufacture products without an OEM license and without any relation to the OEM manufacturer), and contracted remanufacturing companies (a companies that are authorized and contracted by an OEM to remanufacture products).

A remanufacturing industry has been established in several countries, including the United States and some European countries (for instance, see $[19,20]$ ). The following are examples of remanufacturing in the Asian countries.

Matsumoto and Umeda [3] conducted case study analyses on remanufacturing practices in Japan in four product areas, namely photocopiers, single-use cameras, auto parts, and ink and toner cartridges for printers. The results indicate that the motives of OEM remanufacturing companies are long-term economic and environmental incentives, while for independent remanufacturers, it is often because OEMs shun remanufacturing because they are afraid that it will cannibalize new product sales. Matsumoto and Umeda [3] also state that the requirements for remanufacturing are the collection of used products, efficient remanufacturing processes, and demand for remanufactured products.

Yusop et al. [21] conducted a survey to gain insights on how well remanufacturing is being implemented in Malaysia. They find that remanufacturing is considered to be in its infancy in the country, and most respondents have concerns about the quality assurance level.

Abdulrahman et al. [22] studied remanufacturing practices in China. They state that there are five strategic factors that influence a remanufacturing decision, namely the technical, market, regulatory and environmental, financial, and management support factors. Abdulrahman et al. [22] also indicate that Chinese firms are keen to adopt an in-house remanufacturing practice compared to outsourcing despite a lack of technical and managerial capabilities.

\subsection{Uncertainties in Remanufacturing}

According to Guide [19], there are seven characteristics that can become bottlenecks in remanufacturing production planning and control activities.

a. Uncertainty over the return time and the quantity of cores that customers will return.

Uncertainty over the return time, and the quantity of returned cores, is caused by uncertainty over a product's life-cycle and improvements in technology. At the beginning of a product's life-cycle, 
there is only a small number of cores in the market due to the low number of returned cores, and this leads to a relatively expensive core price. In the next phase of the cycle, the demand and supply reach equilibrium. At the end of the cycle, there would be an excess of core supply, leading to a reduction in the core price [13].

b. A balance between returns and demand.

A balance between the quantity of returned cores and remanufactured product demand is crucial to ensure a company's ability to generate operational profit [19]. Too many returns will lead to an excessive inventory cost, while a high level of demand may lead to a low customer service level. To balance the number of returned cores with demand, a forecasting method or the actual demand rate could be used, or the two could even be combined.

c. The disassembly process for returned cores.

According to Guide [19], the disassembly process in remanufacturing is considered to be crucial as the process influences material management, production planning, resource control, and factory control. In this process, miscoordination among departments could instigate a serious inventory problem and issues of customer service quality. This process also produces a recommendation for the replacement of broken spare parts after a visual inspection and an assessment using supporting aids, such as dimension measurement. The disassembly's duration (the lead time) varies from $5.54 \mathrm{~h}$ to $300 \mathrm{~h}$ depending on the model of the component that is being disassembled, the difficulty level, and the spare part recommendation process's duration.

d. Uncertainty over material recovery from the returned cores.

There is no guarantee for the condition of the spare parts in the returned cores. For instance, after disassembly, a part might be able to be reused, reused with repair, or even thrown away as scrap. To forecast the amount of reusable spare parts, a Material Recovery Rate (MRR) matrix could be utilized [19].

e. The need for a reverse logistics network.

Reverse logistics is a process where a product is collected from its end-users and sent to the remanufacturing facility for further repair [19]. The availability of a network to collect returns is the key to success to create a balance between supply and demand. In industries such as the automotive and heavy materials industries, a trade-in between the customer and producer is very common. Another typical model is by using a broker or third party who bridges the gap between the end user and the remanufacturing producer by means of particular incentives.

f. A constraint regarding material compatibility.

A problem may arise where a customer requests that the core products sent to the remanufacturing facility be returned in the very same core unit that was previously sent. In that unit, the assembly process may have used a mix of spare parts or other components from other units. This adds more difficulty to resource planning, factory area control, and material management. Compatibility among materials requires thorough coordination within the assembly team [19].

g. A routing stochastic problem for remanufacturing materials and the wide range of time needed for processing.

Stochastic routings reflect the uncertainty over the core units that will be received as returns from customers. The situation leads to a problem in determining the time needed to process, and plan for, the machinery and manpower. To tackle the problem, a maximum operation time is set up for each 
core, even though it may only require a part of the set operation time. Different cores' conditions also cause a problem in determining the time needed to set up a machine for repair.

Furthermore, according to Behret and Korugan [23], the disassembly and salvaging processes should be done separately from the reassembly process, because they have different levels of uncertainty.

\subsection{Core Acquisition Management and Parts Commonality}

Cores are an essential part of the remanufacturing process as they are considered to be the raw material. Core acquisition management is the activity of obtaining the right cores in terms of quality and amount in a timely manner [24]. According to Gaur et al. [25], core acquisition is one of the most important parts of the closed-loop supply chain because all other activities depend on it. It does not only determine a remanufacturing business's profit, but it is also crucial for determining other operational aspects, such as production planning and control, as well as inventory policy [11]. Guide and Jayaraman [26] were the first to officially introduce product acquisition management as an interface that connects reverse logistic activity to production planning and control so that these two can create synergy for value-added recovery. Based on Guide and Jayaraman [26], the main function of product acquisition management is to reduce the uncertainty level of returns and improve the balance of supply and demand.

In the disassembly process, the task becomes more challenging if it also considers parts commonality, i.e., a product or a subassembly shares its parts or components with other parts/subassemblies [27]. This challenging situation is due to those returned cores that have some parts in common, and an additional dependency between the common parts. Such a commonality enables the exchange of dissembled parts.

\subsection{The In-Plant Materials Supply System}

Production (remanufacturing) logistics plays an important role in the production system, and one of its objectives is to decrease the production lead time [28]. Production logistics is located in the middle of the supply chain; therefore, its performance is affected by the characteristics of suppliers and customers [28], including the uncertainty over raw material supply. One aspect of production logistics is the in-plant materials supply system, and, according to Korytskowski and Karkoszka [29], the efficiency of the in-plant materials supply system is affected by the details of its configuration. Milk-run-based in-plant supply has been very popular in recent years, especially in the automotive industry [28]. In a milk-run environment, the operator works over an area, and supplies several workstations according to a certain route, just like a milkman [29]. Detailed studies on milk-run-based in-plant supply can be seen, for instance, in [28-30].

\subsection{A Summary of the Literature Review}

The above literature review (see Table 1 for the papers discussed in this section) indicates that remanufacturing is growing due to pressures from the government and the opportunity to realize its potential benefit. However, remanufacturing may pose some challenges due to its uncertain nature, especially in core supply (quantity, quality, and timing), that may cause production delays leading to customer dissatisfaction. Thus, a study that focuses on reducing the impact of uncertainty on production delays still needs to be conducted. 
Table 1. A summary of the literature review.

\begin{tabular}{ll}
\hline \multicolumn{1}{c}{ Description } & \multicolumn{1}{c}{ References } \\
\hline Remanufacturing's definition and activities & $\begin{array}{l}\text { Thierry et al. (1995) [1], Geyer and Van Wasenhove (2007) [2], Tang } \\
\text { et al. (2007) [7], Ostlin (2008) [12], and Steinhilper (1998) [13] }\end{array}$ \\
\hline The remanufacturing industry & $\begin{array}{l}\text { Matsumoto and Umeda (2011) [3], Tian et al. (2014) [18], Guide } \\
(2000) \text { [19], Ostlin et al. (2008) [20], Yusop et al. (2012) [21], and } \\
\text { Abdulrahman (2015) [22] }\end{array}$ \\
\hline Uncertainties in remanufacturing & Guide (2000) [19] and Behret and Korugan (2009) [23] \\
\hline Core acquisition and parts commonality & $\begin{array}{l}\text { Guide and Van Wassenhove (2001) [11], Wei et al. (2015) [24], Gaur } \\
\text { et al. (2017) [25], Guide and Jayaraman (2000) [26], and Gagnon } \\
\text { and Morgan (2008) [27] }\end{array}$ \\
\hline In-plant materials supply & $\begin{array}{l}\text { Mácsay and Bányai (2017) [28], Korytkowski and Karkoszka (2016) } \\
\text { [29], and Bányai et al. (2018) [30] }\end{array}$ \\
\hline
\end{tabular}

\section{Research Methodology}

This research aims at identifying the root cause of the operations problem related to the availability of reusable parts that causes delays in the remanufacturing process and propose a solution to the problem. In order to formulate the proper solutions, we conduct a root cause analysis by using a fishbone diagram based on in-depth interviews (IDIs) with representatives from HeavyEq, secondary data from HeavyEq, and the literature review. The fishbone diagram is developed by identifying all problems that become causes of remanufacturing delay, and, after that, we map all subproblems that instigate the identified problems. A Pareto analysis is then employed to determine the priority of the problem solving, and solutions are proposed based on the literature and IDI results.

The informants of the interviews are:

1. The President Director. This person has a background in the production field and is responsible for ensuring the production's punctuality.

2. The Production Planning and Control Director. This person is in charge of production planning, marketing, and material availability, including in the warehouse.

3. The Core management officer. This person is accountable for ensuring that cores are available, which also includes doing correspondence with regional companies to ensure that cores are being delivered as per the schedule. The core management officer is also responsible for seeking out alternative core sources.

HeavyEq's customers are actually its subsidiary companies in every region that deliver remanufactured products to distributors/dealers, who in turn distribute the products to the end customers. Information related to end customers was also obtained from the abovementioned informants as HeavyEq conducts a monthly video/teleconference with its subsidiary companies.

As previously mentioned, this research also uses internal data from HeavyEq as secondary data. The data were obtained from several departments that were involved in HeavyEq's remanufacturing process during the period of August 2015 to October 2015. The data is related to the following:

1. Production (reassembly) delays.

2. The arrival of new parts prior to the remanufacturing production process.

3. Core arrival delays.

4. The sales lead time.

5. Sales backlog data that show purchase orders from customers that have not yet been delivered.

Based on the IDI results and an analysis of the secondary data, factors contributing to delays in the remanufacturing process are presented in the fishbone diagram. Solutions are then proposed based on the interview results and the literature, such as $[12,24,31]$. The effectiveness of the solution is determined using the parameters delay in the reassembly process, sales lead time, and sales backlog. 


\section{Findings and Discussions}

\subsection{HeavyEq's Remanufacturing Activities and Problem}

HeavyEq was established in 2007, and it is an Indonesian company that specifically remanufactures heavy diesel engines for mining applications. In 2017, the company merged with its parent company, an OEM that produces heavy equipment. Hence, the company now produces new and remanufactured products. From here on, 'HeavyEq' refers to that part of the company that produces remanufactured products. The end customers of HeavyEq mainly come from Europe, Africa, the U.S., South America, Australia, and Southeast Asia. The end customers are companies in several mining industries, such as gold, diamond, and coal mining. HeavyEq has 278 employees, with 220 people in production and 58 people in production planning, material control, and warehousing. Currently, HeavyEq has a production volume that reaches 100 main components per month, which comprises engines, powertrains, and hydraulic pumps. The sales volume in 2015 was about USD 46.9 million.

Figure 1 depicts the sequence of remanufacturing activities at HeavyEq. Each element in the sequence is explained as follows:

1. The core receiving process and opening a job order: The returned cores are received and registered, and a new job order (JO) will be created for each returned core. The JO will be assigned to the returned core until it is completely reassembled in the reassembly process.

2. Core inspection: The returned cores undergo a physical inspection to assess whether the outer components are intact.

3. Core disassembly and parts recommendations: The returned cores are disassembled and recommendations regarding the reusability (reusable/recondition/scrap) of the disassembled parts are made using the Part Recommendation System (PRS) software. If a part is recommended to be scrapped, the system will check for the availability of a spare part at the warehouse, and order the spare part. At the same time, the quality assurance department issues a Strip Down Report, comprising the condition (quality) of each disassembled part. In the report, the returned cores are classified into Category A (if all parts from the returned cores are reusable), Category B (if one of the following parts is not reusable: the cylinder head, the flywheel, the flywheel housing, the crankshaft, or the camshaft), and Category C (if one of the following parts is not reusable: the cylinder block or the crankshaft). HeavyEq will order new parts earlier in the process based on forecasting, and may issue another order for new parts if, based on the recommendation, the percentage of reusable parts is less than predicted. Since the part manufacturers are located in Japan, the lead time on an order for new parts is about 2.5 months.

4. Washing: The aim of this process is to remove paints, lubricants, and other residues. To avoid rust, a base layer is painted on the cleaned and disassembled parts.

5. Salvaging/reconditioning: This process is performed if the disassembled parts can be reused but need to be fixed or reconditioned.

6. Re-checking: This process is conducted to ensure that the amount and quality of parts for the remanufacturing process is as required. In this process, each part is given a part number as in the manual book, and the parts are then stored in the reuse warehouse.

7. Kitting: When the schedule for reassembly is issued, all parts (reused and new) are released from the warehouse and grouped by the Kitting Section to make it easier for the mechanics to assemble them.

8. Subcomponents reassembly: The Subassembly Section assembles the parts into subcomponents, which are later sent to the engine reassembly section (the main assembly line).

9. Shortblock reassembly: In this process, most of the important parts (the cylinder block, the crankshaft, the connecting rod, pistons, the cylinder liner, the camshaft, and the oil pump) are reassembled. 
10. Engine reassembly: In this process, components from the Shortblock Reassembly process are assembled with subcomponents from the Subcomponents Reassembly process to create the complete remanufactured engine.

11. Performance test: The remanufactured engines undergo a performance test to ensure that their quality is similar to that of new ones. If the performance does not meet the requirement, the engine will undergo reinspection and retesting until all requirements are met.

12. Painting: In this process, the remanufactured engines are painted with a top coat.

13. Final inspection: The Quality Assurance Department will conduct a final inspection to make sure that the quality standard is met and the configuration is as demanded by the customer.

14. Wrapping: This process is done to protect the remanufactured engine from contamination and rust during the delivery process.

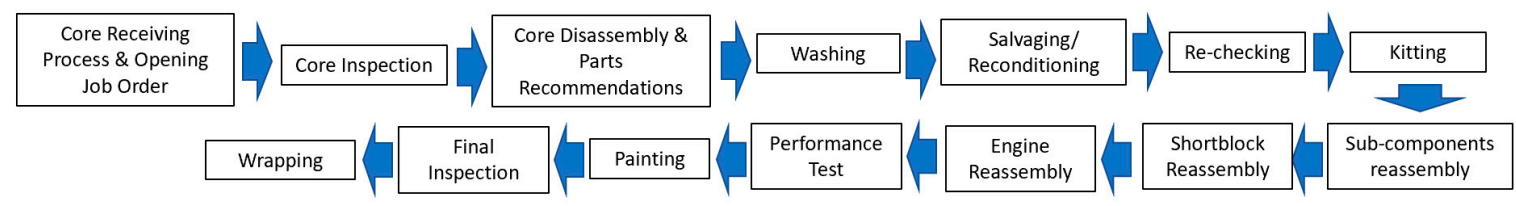

Figure 1. The remanufacturing activities at HeavyEq.

The remanufacturing activities need 162 days in total to complete (see Figure 2).

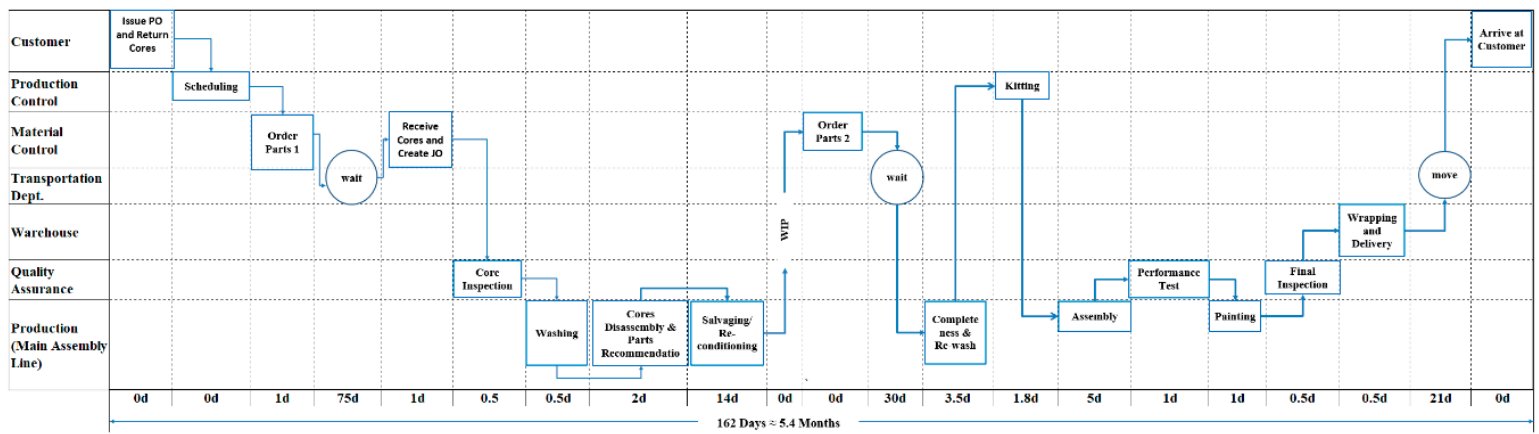

Figure 2. A time function map of the remanufacturing activities.

HeavyEq faces uncertainty over the availability/supply of parts during the engine remanufacturing process. This is caused by the late arrival of cores, which affects the remanufacturing process negatively. Some examples are as follows.

a. The late arrival of new parts (to replace parts that cannot be reused). Table 2 shows the late arrival of new parts in the period of August 2015 to October 2015. It can be seen that only 16.5\% of new parts are received a week prior to the production starting time, while $27.8 \%$ are received in the first week of the production month, and the other $55.7 \%$ are received in the second week.

b. A failure to complete the assembly process on a timely basis, which leads to a failure to deliver the remanufactured products on time. Table 3 shows that, during the production, the total reassembly delay for the same period was 566 days. Table 4 presents the sales backlog (the total backlog in the period of August 2015 to October 2015 is 141 units, which is worth around USD 5.2 million). Table 5 shows the sales lead time (the average is 4.10 months).

c. Lower productivity and work efficiency of reassembly process workers due to the excessive amount of idle time.

d. Underutilized production (reassembly) capacity.

e. Difficulty in efficiently managing workload and capacity, where the tendency for overtime drastically increases when approaching a deadline due to the late arrival of the new parts. 
Table 2. The new parts' arrival time (August 2015 to October 2015).

\begin{tabular}{ccc}
\hline Arrival Time & Number of Jobs & Percentage \\
\hline N-1 Week & 16 & 16.5 \\
Week 1 & 27 & 27.8 \\
Week 2 & 54 & 55.7 \\
\hline Note: N $=$ Production (reassembly) starting time.
\end{tabular}

Table 3. The reassembly delay time (August 2015 to October 2015).

\begin{tabular}{ccc}
\hline Month & Delay Time (Days) & Number of Delayed Job Orders \\
\hline August & 182 & 34 \\
September & 208 & 32 \\
October & 176 & 31 \\
Total & 566 & 97 \\
\hline
\end{tabular}

Table 4. The sales backlog (August 2015 to October 2015).

\begin{tabular}{ccc}
\hline Month & Backlog (Units) & Value (USD) \\
\hline August & 40 & $1,621,477$ \\
September & 52 & $1,914,597$ \\
October & 49 & $1,675,546$ \\
Total & 141 & $5,211,620$ \\
\hline
\end{tabular}

Table 5. The sales lead time (August 2015 to October 2015).

\begin{tabular}{cc}
\hline Month & Sales Lead Time (Months) \\
\hline August & 4.25 \\
September & 4.4 \\
October & 3.65 \\
Average & 4.10 \\
\hline
\end{tabular}

\subsection{Root Cause Analysis}

As previously explained, a fishbone diagram was used as a tool to identify the root causes of the problem. Figure 3 presents the fishbone diagram, which shows that delays in the remanufacturing process are generated by the following four main problems:

a. A late arrival, and an inadequate quantity, of returned cores (as raw materials). This situation causes the ordering of new parts (to replace parts that cannot be reused) to be postponed due to the delay in obtaining information about the parts' condition after the disassembly process.

b. The percentage of reusable parts from the returned cores is less than predicted. This situation will affect the second stage of an order, particularly when a high percentage of reusable spare parts (more than $70 \%$ ) was predicted that does not match with the actual percentage, and the types of spare parts are vital, such as cylinder blocks.

c. The types of returned cores are incompatible with the production requirements, meaning that HeavyEq has returned cores that could not be processed due to their being incompatible, which causes dead stock to accumulate.

d. A discrepancy between the reassembly (production) and disassembly schedules. The late arrival of returned cores makes it very difficult for the scheduling department to put them into an ongoing disassembly process. Consequently, the returned cores will then be scheduled for disassembly in the following month/period. It can be seen in Table 6 that some returned cores are arriving less than a month prior to the reassembly process. This situation makes it difficult to order the new parts. 


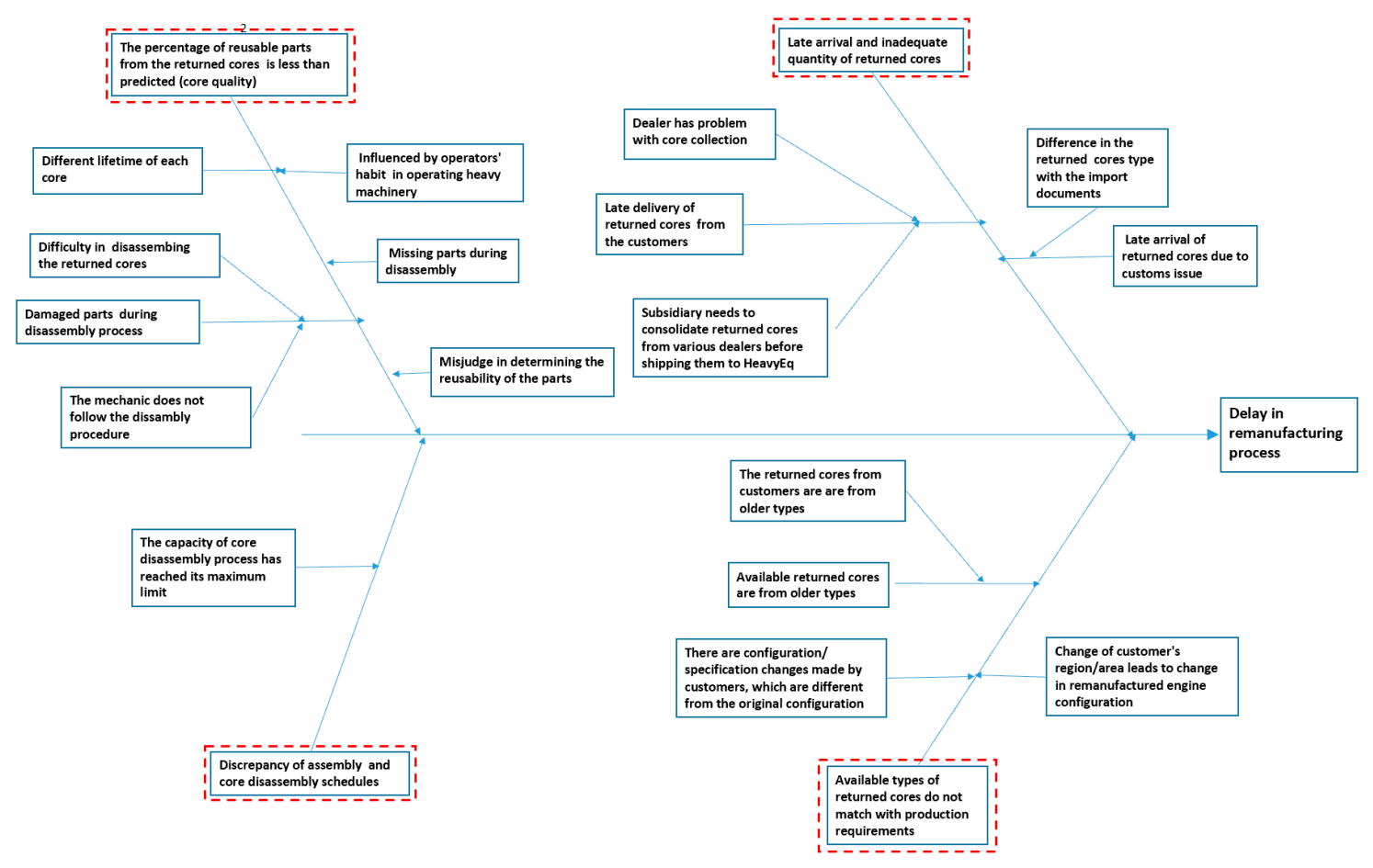

Figure 3. The fishbone diagram.

Table 6. The arrival of returned cores one month before the production time (October 2015).

\begin{tabular}{cc}
\hline Arrival Time & Number of Jobs \\
\hline Week 1 & 11 \\
Week 2 & 8 \\
Week 3 & 4 \\
Week 4 & 2 \\
\hline
\end{tabular}

Each of the above four problems is caused by the subproblems that can be seen in the fishbone diagram. For instance, the late arrival, and an inadequate quantity, of returned cores are caused by late deliveries by customers and custom issues, and the custom issues themselves are caused by differences between the returned cores' types and what is stated in the import documents.

HeavyEq's operations problems are similar to those explained in the literature. Guide [19] and Guide and Jayaraman [26] state that the uncertainties over the return time and the amount of returned cores reflect the nature of product life-cycle uncertainty. Furthermore, uncertainty over the recovered materials may cause two recovered spare parts to be of different quality. Similarly, Wei et al. [24] mention that the characteristics of the main problem in remanufacturing operations are the arrival of returned cores that is not at the time and quantity needed, and the uncertainty over the returned cores' quality.

\subsection{Determining the Priority}

These problems require proper solutions to ensure that the remanufacturing process runs smoothly. In order to do that, a priority needs to be set, as this has a great impact on the remanufacturing process. Table 7 presents HeavyEq's remanufacturing problems and their frequencies for the period of August 2015 to October 2015.

As can be seen in Table 7, the first three problems are two of the main problems depicted in the fishbone diagram. Thus, the late arrival, and inadequate quantity, of returned cores, and a lower percentage of reusable spare parts from the returned cores, are set as the problems to be solved in this study. 
Table 7. HeavyEq's problems for the period August 2015 to October 2015.

\begin{tabular}{clcc}
\hline No. & \multicolumn{1}{c}{ Problem } & Frequency & Percentage \\
\hline 1 & The returned cores do not arrive at the required time (delayed) & 27 & 36.00 \\
\hline 2 & The quantity of the returned cores is not as required (inadequate) & 20 & 26.67 \\
\hline 3 & $\begin{array}{l}\text { The percentage of reusable spare parts from the returned cores is less } \\
\text { than predicted (core quality) }\end{array}$ & 14 & 18.67 \\
\hline 4 & $\begin{array}{l}\text { The available types of returned cores do not match with the } \\
\text { production requirements }\end{array}$ & 3 & 10.67 \\
\hline 5 & A discrepancy between the assembly and disassembly schedules & 2 & 2.00 \\
\hline 6 & The late arrival of new spare parts due to mistakes during the order & 2 & 1.33 \\
\hline 7 & $\begin{array}{l}\text { The change in the percentage of reusable spare parts is not followed } \\
\text { by revision of the material requirement planning (MRP) }\end{array}$ & 1 & 100 \\
\hline
\end{tabular}

\subsection{The Proposed Solutions}

Using a combination of in-depth interviews (IDIs) with the experts at HeavyEq and the relevant literature, solutions to the two prioritized main problems are proposed.

\subsubsection{The Late Arrival, and an Inadequate Quantity, of Returned Cores}

The fishbone diagram shows two subproblems that cause the late arrival, and an inadequate quantity, of returned cores that are related to core acquisition problem, namely:

1. The late delivery of returned cores by the customers. This is usually due to geographical reasons: the used cores come from mining sites in remote areas, whereas the office or warehouse facility is located in a different city, which causes logistics problems.

2. Customs issues. If the documents and the physical condition of the imported core do not match, customs will not grant an exit permit from the seaport.

Regarding the above problem, HeavyEq has implemented the following initiatives:

1. Communicating extensively with each customer to remind them about the returned core(s), and also monitoring the delivery activity.

2. Asking each customer to make sure that the export/import documents contain the correct product information (such as a core's serial number).

However, these initiatives have not improved the situation significantly. Thus, other efforts are required. The following are the proposed solutions to the problem:

1. Collect the cores from diverse sources (customers, dealers, distributors) $[19,26]$. Some methods to do such core collection are: deposit, leasing, trade-in [24], or establishing a bank of cores. The collected cores should not be limited to certain types, so that HeavyEq can obtain a wide variety of cores in a large quantity.

2. Offer an attractive core return scheme to customers. According to Guide and Jayaraman [26], returned cores come from end users $(81.8 \%)$, brokers $(9.2 \%)$, third party agents $(7.3 \%)$, and seed stock $(1.7 \%)$. To reduce the number of unreturned cores, an attractive incentive scheme must be created. One method to do this is a deposit-refund system. In this mechanism, HeavyEq can charge a certain deposit fee when selling remanufactured products to its customers, which can be fully or partially refundable, depending on the returned cores' quality [26]. In the case where a customer does not return a used core to HeavyEq as it is supposed to, HeavyEq can charge the customer for the price of a brand new engine on the remanufactured product by assuming 
that the core has zero value. Some other systems that can be used are buy-back, voluntary-based, ownership-based, direct-order, credit-based, and service-contract-based systems [20].

3. Request that customers take a photograph of the cores' serial numbers $(\mathrm{S} / \mathrm{N})$ and their configurations prior to shipping, and send them to HeavyEq. Therefore, in the case where the documents and the physical condition of the imported cores do not match, the documents can be revised before the arrival of the containers based on the received photographs.

\subsubsection{The Percentage of Reusable Parts from the Returned Cores is Less than Predicted}

As can be seen in the fishbone diagram, there are subproblems that cause the percentage of reusable parts to be less than predicted. The quality of returned cores (and the disassembled parts) in remanufactured products vary, because the economic life of the cores might be different, the engine's operational costs might be different, which influences the economic life of the cores, the wrong disassembly method might be used, and a misjudgment might occur in determining the reusability of the spare parts. HeavyEq has attempted to solve the problem by:

1. Classifying the returned cores into three groups (A, B, and C) based on the actual condition of the parts after the disassembly process is complete, as explained in Section 4.1. These initiatives have also been mentioned in other studies, such as in [24].

2. Conducting research to find a better method to recover the cores' parts. This can help to minimize uncertainty over the returned cores' quality, as most of the used parts can be recovered.

3. Improving the spare part forecasting method by comparing every 10 job orders for similar engine types to obtain the trend of the reusable percentage of certain spare parts. This percentage is then used as a benchmark for ordering in MRP.

4. Improving the safety stock level of the critical parts to ensure their availability. A safety stock is especially for parts with a short lifetime, and it is useful to anticipate any inaccurate forecasts.

However, the above efforts have not been enough to solve the problem. The following are the proposed solutions to the problem:

1. As disassembly and salvaging processes have different levels of uncertainty [23], we propose that HeavyEq separate job orders for the disassembly process from job orders for the reassembly process. By doing it this way, there will be no relation between the status of spare parts that will be used in the disassembly and recovery processes with spare parts that will be used in the reassembly process. In the previous arrangement, if the production (reassembly) schedule has not been started, even though the returned cores have been disassembled, and the parts have been assessed and recovered (fixed), these parts will be assigned the status of work-in-process (WIP) and stored in the warehouse. Hence, if there is any other job order that needs similar parts, it cannot use the WIP spare parts, even though they are available in the warehouse. By implementing two separate job orders, the whole process becomes more flexible, as disassembled parts do not have WIP status and can be used for the reassembly process in any job order. This will lead to a shortened production lead time.

2. Reassembling the used parts into subcomponents should be done as early as possible after the returned cores are received, disassembled, cleaned, assessed, and repaired. By preparing the required subcomponents as early as possible, the uncertainty over the quality of the returns can be minimized so that the remanufacturing process can run smoothly.

3. Following the separation of job orders for disassembly and recovery from job orders for reassembly processes, changes in the assessment of returned cores must be carried out as well. Previously, the assessment of all WIP parts from a returned core was conducted on a whole unit. This arrangement introduces inflexibility into the process. In the new arrangement, the assessment of the returned cores is done based on an inspection of its parts. Thus, each part has its own price based on its condition, and, in the reassembly process, the cost of the part is the sum of its components' prices. 
The proposed solutions have the following implications. A change in the enterprise resource planning (ERP) must be carried out to accommodate the establishment of a bank of cores, the job order separation, and the assessment of returned cores based on each disassembled part's condition. Extensive communication with customers, dealers, and distributors must also be conducted to explain the benefit of the return scheme and to ensure the timely return of cores.

\subsection{The Condition after the Implementation of Proposed Solutions}

Referring to the literature on remanufacturing, one of the difficulties in the remanufacturing process is a high level of uncertainty, which is the main characteristic of remanufacturing [19]. HeavyEq started to implement the proposed solutions in early 2016. The delay in the reassembly process, the sales lead time, and the sales backlog in the period of March 2016 to May 2016 are presented in Tables 8-10.

Table 8. The reassembly delay time (March 2016 to May 2016).

\begin{tabular}{ccc}
\hline Month & Delay Time (Days) & Number of Delayed Job Orders \\
\hline March & 78 & 37 \\
April & 38 & 35 \\
May & 152 & 49 \\
Total & 268 & 121 \\
\hline
\end{tabular}

Table 9. The sales backlog (March 2016 to May 2016).

\begin{tabular}{ccc}
\hline Month & Backlog (Units) & Value (USD) \\
\hline March & 6 & 644,250 \\
April & 11 & 351,997 \\
May & 49 & $2,036,320$ \\
Total & 66 & $3,032,567$ \\
\hline
\end{tabular}

Table 10. The sales lead time (March 2016 to May 2016).

\begin{tabular}{cc}
\hline Month & Sales Lead Time (Months) \\
\hline March & 2.8 \\
April & 3.1 \\
May & 2.6 \\
Average & 2.83 \\
\hline
\end{tabular}

As can be seen in the above tables, the implementation of the proposed solutions has had positive impacts on HeavyEq's remanufacturing process. By establishing a bank of cores, and offering a more attractive core return scheme to its customers, the company has better control over core acquisition [24], and, thus, the number of returned cores has increased, and the availability of reusable parts has improved, leading to a reduction in remanufacturing delay from 566 days to 268 days (see Table 8). Furthermore, by separating the job orders for disassembly and recovery from the job orders for reassembly, parts within one core can be exchanged with parts from other job orders (free-floating). As a result, the process has become more flexible, and the availability of reusable parts has increased. Last, by reassembling the subcomponents as early as possible, the waiting time has been reduced, leading to a shortened production (reassembly) lead time and sales backlog (see Tables 9 and 10).

\section{Conclusions}

This paper presents an analysis of the operations problem faced by HeavyEq, an Indonesian remanufacturing company. The company experienced delays in the remanufacturing process, and a root cause analysis showed that the problem was caused by four main problems: the late arrival, and an inadequate quantity, of returned cores; the percentage of reusable parts from the returned 
cores was less than predicted; the types of returned cores were incompatible with the production requirements; and there was a discrepancy between the reassembly and disassembly schedules. As the first two problems occurred frequently, this study focused on analyzing and proposing solutions to these problems.

HeavyEq had implemented some initiatives to solve its problems regarding the late arrival, and an inadequate quantity, of returned cores, and the lower percentage of reusable parts. However, the initiatives did not result in a significant improvement of the company's situation. Therefore, solutions to both problems are proposed based on the results of IDIs with experts at the company and the literature. The proposed solutions were establishing a bank of cores by collecting different varieties of cores from various sources, offering a more attractive core return scheme (such as the deposit-refund system), the reassembly of disassembled parts into subcomponents as early as possible, separating job orders for disassembly and recovery from job orders for reassembly, and assessing the value of returned cores based on the condition of each disassembled part. The proposed solutions were implemented in early 2016, and they were found to reduce delays in the reassembly process, the sales lead time, and the sales backlog.

This study has some limitations. The costs related to the establishment of the bank of cores, and other initiatives, have not been evaluated in this study, and we propose to investigate them in future research.

Lastly, there are lessons that can be learned from this study. First, managers must continue to find ways to improve the remanufacturing operation's performance by evaluating this performance periodically, identifying the problems, and finding the root cause of the problems. Second, even though the uncertain nature of the remanufacturing production system may negatively impact the operation's performance (such as via production delays), the impacts can be reduced by working together with customers and dealers to establish a bank of cores, and by making the production system more flexible.

Author Contributions: E.S. conducted the study and wrote the initial paper; R.D.K. supervised the study and wrote the submitted paper.

Acknowledgments: The authors want to thank all the informants at HeavyEq for their invaluable information.

Conflicts of Interest: The authors declare no conflict of interest.

\section{References}

1. Thierry, M.; Salomon, M.; Van Nunen, J.; Van Wassenhove, L. Strategic issues in product recovery management. Calif. Manag. Rev. 1995, 37, 114-135. [CrossRef]

2. Geyer, R.; Van Wassenhove, L. The Economics of Remanufacturing Under Limited Component Durability and Finite Product Life Cycles. Manag. Sci. 2007, 53, 88-100. [CrossRef]

3. Matsumoto, M.; Umeda, Y. An analysis of remanufacturing practices in Japan. J. Remanuf. $2011,1,2$. [CrossRef]

4. Cummins Inc. Sustainability Progress Report 2016. 2016. Available online: https://www.cummins. com/sites/default/files / files / reports /2017_cummins_sustainability_progress_report_1017.pdf (accessed on 1 June 2018).

5. $\quad$ Blackstone, J.H. APICS Dictionary, 14th ed.; APICS: Chicago, IL, USA, 2013.

6. Stahel, W.R. Caterpillar Remanufactured Products Group. 1995. Available online: http:/ /www.product-life. org/en/archive/case-studies/caterpillar-remanufactured-products-group (accessed on 30 June 2018).

7. Tang, O.; Grubbstrom, R.W.; Zanoni, S. Planned lead time determination in a make-to-order remanufacturing system. Int. J. Prod. Econ. 2007, 108, 426-435. [CrossRef]

8. Asif, F.MA.; Bianchi, C.; Rashid, A.; Nicolescu, C.M. Performance analysis of the closed loop supply chain. J. Remanuf. 2012, 2012. 2, 4. [CrossRef]

9. San, G.S.; Pujawan, I.N. Closed-loop supply chain with remanufacturing: A literature review. In Proceedings of the International Conference on IML 2012, Chicago, IL, USA, 25-29 May 2012. 
10. Krikke, H.R.; Kooi, E.J.; Schuur, P.C. Network Design in Reverse Logistics: A Quantitative Model. In New Trends in Distribution Logistics; Lecture Notes in Economics and Mathematical Systems, Speranza, M.G., Stähly, P., Eds.; Springer: Berlin, Germany, 1990; Volume 480, pp. 45-61.

11. Guide, V.D.R.; Van Wassenhove, L.N. Managing product returns for remanufacturing. Prod. Oper. Manag. 2001, 10, 142-155. [CrossRef]

12. Ostlin, J. Analysis and Managing Material Flow and Remanufacturing Process. Ph.D. Thesis, Linköping University, Linköping, Sweden, 2008.

13. Steinhilper, R. Remanufacturing: The Ultimate Form of Recycling; Fraunhofer IRB Verlag: Stuttgart, Germany, 1998.

14. Fleischmann, M.; Krikke, H.R.; Dekker, R.; Flapper, S.D.P. A characterization of logistics networks for product recovery. Omega 2000, 28, 653-666. [CrossRef]

15. Morgan, S.J.; Gagnon, R.J. A systematic literature review of remanufacturing scheduling. Int. J. Prod. Res. 2013, 51, 4853-4879. [CrossRef]

16. Steinhilper, R.; Hieber, M. Remanufacturing-The Key Solution for Transforming Downcycling into Upcycling of Electronics. In Proceedings of the 2001 IEEE International Symposium on Electronics and the Environment, Denver, CO, USA, 9 May 2001.

17. U.S. Department of Commerce. On the Road: U.S. Automotive Parts Industry Annual Assessment. 2011. Available online: https://www.trade.gov/td/otm/assets/auto/2011Parts.pdf (accessed on 31 August 2018).

18. Tian, G.; Chu, J.; Hu, H.; Li, H. Technology innovation system and its integrated structure for automotive components remanufacturing industry development in China. J. Clean. Prod. 2014, 85, 19-432. [CrossRef]

19. Guide, V.D.R. Production planning and control for remanufacturing: Industry practice and research needs. J. Oper. Manag. 2000, 18, 467-483. [CrossRef]

20. Ostlin, J.; Sundin, E.; Bjorkman, M. Importance of closed-loop supply chain relationships for product remanufacturing. Int. J. Prod. Econ. 2008, 115, 336-348. [CrossRef]

21. Yusop, N.M.; Wahab, D.A.; Saibani, N. Analysis of Remanufacturing Practices in the Malaysian Automotive Industry. J. Teknol. 2012, 59, 77-80.

22. Abdulrahman, M.D.; Subramanian, N.; Liu, C. Viability of remanufacturing practice: A strategic decision-making framework for Chinese auto-parts companies. J. Clean. Prod. 2015, 105, 311-323. [CrossRef]

23. Behret, H.; Korugan, A. Performance analysis of a hybrid system under quality impact of returns. Comput. Ind. Eng. 2009, 56, 507-520. [CrossRef]

24. Wei, S.; Tang, O.; Sundin, E. Core (product) Acquisition Management for remanufacturing: A review. J. Remanuf. 2015, 5, 4. [CrossRef]

25. Gaur, J.; Subramoniam, R.; Govindan, K.; Huisingh, D. Closed-loop supply chain management: From conceptual to an actionoriented framework on core acquisition. J. Clean. Prod. 2017, 167, 1415-1424. [CrossRef]

26. Daniel, V.; Guide, R., Jr.; Jayaraman, V. Product acquisition management: Current industry practice and a proposed framework. Int. J. Prod. Res. 2000, 38, 3779-3800. [CrossRef]

27. Gagnon, R.J.; Morgan, S.D. Scheduling remanufacturing operations: A literature review and analysis. In Proceedings of the 2008 Annual Meeting of the South Eastern Institute for Operations Research and the Management Sciences, Myrtle Beach, SC, USA, 3-4 October 2008.

28. Mácsay, V.; Bányai, T. Toyota Production System in Milkrun Based in-Plant Supply. J. Prod. Eng. 2017, 20, 141-146. [CrossRef]

29. Korytkowski, P.; Karkoszka, R. Simulation-based efficiency analysis of an in-plant milk-run operator under disturbances. Int. J. Adv. Manuf. Technol. 2016, 82, 827-837. [CrossRef]

30. Bányai, T.; Telek, P.; Landschützer, C. Milkrun Based In-plant Supply-An Automotive Approach. In Vehicle and Automotive Engineering 2, Proceedings of the 2nd VAE 2018, Miskolc, Hungary, 23-25 May 2018; Jármai, K., Bolló, B., Eds.; Springer: Cham, Switzerland, 2018; pp. 170-185.

31. Sundin, E.; Bras, B. Making functional sales environmentally and economically beneficial through product remanufacturing. J. Clean. Prod. 2005, 13, 913-925. [CrossRef]

(C) 2018 by the authors. Licensee MDPI, Basel, Switzerland. This article is an open access article distributed under the terms and conditions of the Creative Commons Attribution (CC BY) license (http://creativecommons.org/licenses/by/4.0/). 